\title{
Kinetic and Equilibrium Studies of Coomassie Blue G-250 Adsorption on Apricot Stone Activated Carbon
}

\author{
Abbas Moussa $^{1 *}$, Cherfi Abdelhamid ${ }^{2}$, Kaddour Samia $^{3}$, Aksil Tounsia $^{1}$ and Trari Mohamed ${ }^{4}$ \\ ${ }^{1}$ Laboratory of Soft Technologies and Biodiversity (LTDVPMBB), Faculty of Sciences, University M'hamed Bougara of Boumerdes (UMBB), 35000, Algeria \\ ${ }^{2}$ Faculty of Sciences, Chemical Department, University M'hamed Bougara of Boumerdes (UMBB), 35000, Algeria \\ ${ }^{3}$ Laboratory of Macromolecular, Synthesis and Macromolecular Thio-organic, Faculty of Chemistry (USTHB), BP 32- 16111, El-Alia, Algeria \\ ${ }^{4}$ Laboratory of Storage and Valorization of Renewable Energy, Faculty of Chemistry (USTHB), BP 32- 16111, El-Alia, Algeria
}

\begin{abstract}
The preparation of Activated Carbon from Apricot Stone (ASAC) with $\mathrm{H} 3 \mathrm{PO} 4$ and its ability to remove the Coomassie Blue (CB) used in textile industry from aqueous solutions are reported in this study. The FTIR spectroscopy is used to get information on interactions between the adsorbent and CB. A series of contact time experiments were undertaken in stirred batch adsorber to assess the effect of the system variables. The results were discussed and showed that ASAC can be used in the wastewater treatment. A comparison of two models on the overall adsorption rate showed that the kinetic of adsorption was better described by the pseudo-second order model. The adsorption isotherms of CB onto ASAC are determined and correlated with common isotherms equations. The smaller RMSE values obtained for the Freundlich model indicate the better curve fitting; the monolayer adsorption capacity of CB is found to be $10.09 \mathrm{mg} / \mathrm{g}$ at temperature $22.5^{\circ} \mathrm{C}$ and $98.022 \mathrm{mg} / \mathrm{g}$ at temperature $50{ }^{\circ} \mathrm{C}$ and $\mathrm{pH} \sim 2$. The thermodynamic parameters indicate the spontaneous and exothermic nature of the adsorption process. The positive value of the entropy $(\Delta S)$ clearly that the randomness in decreased at the solid-solution interface during the $\mathrm{CB}$ adsorption onto ASAC, indicating that some structural exchange may occur among the active sites of the adsorbent and the ions. The activation energy (66.161 kJ/ $\mathrm{mol}$ ) indicates that the chemical adsorption was predominant.
\end{abstract}

Keywords: Apricot stone; Coomassie Blue G-250; Kinetic; Isotherm; Thermodynamic

\section{Introduction}

The dye production plants and many other industries which utilize dyes are increasing globally by the day with advancement in technology [1-3]. Textile, leather, paper, plastic, food, cosmetics, etc. are some of these industries. Presently, it was estimated that about 100000 of different commercial dyes and pigments exist and over 7.105 tones are produced annually worldwide [4,5]. As a result, the water pollution by dyes has become one of the major pollution sources with approximately over 40000 tones of dyes released every year into the environment $[5,6]$. Furthermore, most dyes are resistant to heat and light and are not biodegradable [5]. Their presence in wastewater causes the water pollution by lowering light penetration and in this way the photosynthesis [3]. Hence, the removal of dyes from waste effluents has become environmentally important. Various processes have been investigated and found to be effective in reducing dye concentrations in wastewaters like the chemical oxidation, biological treatment, coagulation-flocculation, membrane processes, adsorption, etc. $[7,8]$. Among these methods, the adsorption onto activated carbon has been found to be superior, inexpensive and effective to treat many dyes in wastewaters $[5,7,8]$. The high adsorption capacity of activated carbon is a result of a high surface area, extensive porosity in the interior of the particles, and presence of many different types of surface functional groups [5]. However, the available activated carbons in commerce are relatively expensive; their production and regeneration cost may constitute their limiting factors [6]. Hence, most researchers worldwide have focused on the search of new low-cost precursors especially issued from agricultural wastes. The precursors from wastes and agricultural by-products such as dolomite [8], date stones [9], waste bamboo scaffolding [5], Wheat Bran [10], bagasse [7] and flamboyant Pods [11] have shown a great absorption potential. The objective of the present study was to use apricot stones as a low-cost precursor since agriculture in Algeria generates more than 20.000 tones of apricot stones each year, and represents a significant amount of solid pollutant. The aim of the study was to assess the ability of activated carbon prepared from apricot stones for the removal of Coomassie blue (G-250), an acid dye largely used in the textile industry and biology and biochemistry for staining proteins [12]. The study was carried out with the aim to optimize the conditions for maximum removal of this dye from aqueous solutions. Besides this, the equilibrium adsorption data were fitted to various models to obtain constants related to the adsorption process. Finally, the thermodynamic and kinetic studies were performed in order to estimate the rate of adsorption in parallel with the activation energy and changes in the free energy, enthalpy and entropy.

\section{Experimental}

\section{Materials and methods}

Analytical grade reagents are used in all experiments. Acid dye, $\mathrm{CB}$ $(99 \%)$ is purchased from Merck Company. The chemical structure and properties of CB are listed in Table 1. Apricot stones obtained from Boumerdes region in Algeria, are air-dried, crushed and screened to obtain two fractions with geometrical mean sizes ranging from 63 to 2.5 $\mathrm{mm} .100 \mathrm{~g}$ of the selected fraction are impregnated with concentrated

*Corresponding author: Moussa A, Laboratory of Soft Technologies and Biodiversity (LTDVPMBB), Faculty of Sciences, University M'hamed Bougara of Boumerdes (UMBB), 35000, Algeria, Tel: +213-024-91-11-16; E-mail: moussaiap@ gmail.com

Received December 23, 2014; Accepted January 18, 2015; Published January 24, 2015

Citation: Moussa A, Abdelhamid C, Samia K, Tounsia A, Mohamed T (2015) Kinetic and Equilibrium Studies of Coomassie Blue G-250 Adsorption on Apricot Stone Activated Carbon. J Environ Anal Toxicol 5: 264. doi:10.4172/21610525.1000264

Copyright: @ 2015 Moussa A, et al. This is an open-access article distributed under the terms of the Creative Commons Attribution License, which permits unrestricted use, distribution, and reproduction in any medium, provided the original author and source are credited. 
$\mathrm{H}_{3} \mathrm{PO}_{4}(85 \%)$ and dried in air. Then, it is activated in a hot air oven at $250^{\circ} \mathrm{C}(4 \mathrm{~h})$. The carbonized material is washed with distilled water to remove the free acid until the $\mathrm{pH}$ reaches 6.8 and dried at $105^{\circ} \mathrm{C}$. The clean biomass is mechanically ground and sifted to get a powder of different particle sizes: < 63, [63-80], [80-100], [100-200], [200315], [315-800] $\mu \mathrm{m}$ and [0.8-1], [1-1.6], [1.6-2] $\mathrm{mm}$. Table 2 gives the physical and chemical properties of the Apricot Stones Activated Carbon (ASAC).

\section{Batch mode adsorption studies}

The effects of the experimental parameters such as the initial $\mathrm{CB}$ concentration (10-100 $\mathrm{mg} / \mathrm{L}), \mathrm{pH}(2-10)$, adsorbent dosage $(1-7 \mathrm{~g} / \mathrm{L})$ and temperature $(295-329 \mathrm{~K})$ on the adsorptive removal of CB ions is studied in a batch mode of operation for a specific period of contact time (0-60 min). The $\mathrm{CB}$ solutions are prepared by dissolving the accurate amount CB (99\%) in distilled water, used as a stock solution and diluted to the required initial concentration. $\mathrm{pH}$ is adjusted with $0.1 \mathrm{~mol} / \mathrm{L} \mathrm{HCl}$ or $0.1 \mathrm{~mol} / \mathrm{L} \mathrm{NaOH}$. For the kinetic studies, desired quantity of ASA is contacted with $10 \mathrm{~mL}$ of $\mathrm{BC}$ solutions in Erlenmeyer flasks. Then, the flasks are placed on a rotary shaker at $300 \mathrm{rpm}$ and the samples are taken at regular time intervals and centrifuged at $3000 \mathrm{rpm}$ for $10 \mathrm{~min}$. The CB content in the supernatant was measured spectrophotometrically on a Perkin Elmer UV-visible spectrophotometer model 550S at wavelength of $595 \mathrm{~nm}$. The amount of CB ions adsorbed by activated carbon $\mathrm{q}_{\mathrm{t}}(\mathrm{mg} / \mathrm{g})$ is calculated by using the following equation (A1):

$$
q_{t}=\frac{\left(c_{0}-c_{e}\right) \cdot V}{m}
$$

Where $\mathrm{C}_{0}$ is the initial $\mathrm{CB}$ concentration and $\mathrm{C}_{t}$ the $\mathrm{CB}$ concentrations $(\mathrm{mg} / \mathrm{L})$ at any time, $V$ the volume of solution $(\mathrm{L})$ and $\mathrm{m}$ the mass of the activated carbon $(\mathrm{g})$.

Due to the inherent bias resulting from linearization of the isotherm and kinetic models, the non-linear regression Root Mean Square Error (RMSE) test is employed as criterion for the quality of fitting [13].

The RMSE of a model is evaluated by the following equation (A2) :

\begin{tabular}{|l|c|}
\hline Brute Formula & $\mathbf{C}_{47} \mathbf{H}_{49} \mathbf{N}_{3} \mathrm{NaO}_{7} \mathbf{S}_{2}$ \\
\hline Molecular weight & $(855.028 \pm 0.054) \mathrm{g} / \mathrm{mol}$ \\
\hline Density & $(0.96 \pm 0.05) \mathrm{g} / \mathrm{mL}$ \\
\hline Wave number $\left(\lambda_{\max }\right)$ & $595 \mathrm{~nm}$ \\
\hline Refractive index & $(1.334 \pm 0.124)$ \\
\hline Name & Coomassie Brilliant Blue (G-250) \\
\hline
\end{tabular}

Table 1: Chemical properties of acid dye, Coomassie Blue (G-250)

\begin{tabular}{|c|c|}
\hline \multicolumn{2}{|c|}{ Elemental analysis (\%) } \\
\hline $\mathrm{C}$ & 48.45 \\
\hline $\mathrm{H}$ & 6.03 \\
\hline $\mathrm{N}$ & 0.44 \\
\hline $\mathrm{O}$ & 45.08 \\
\hline $\mathrm{pHzpc}$ & $(7.05 \pm 0.10)$ \\
\hline Surface area $(\mathrm{m} 2 / \mathrm{g})$ & $(88.05 \pm 1.03)$ \\
\hline Average pore diameter $(\AA)$ & $(176.32 \pm 0.25)$ \\
\hline Average pore volume $(\mathrm{mL} / \mathrm{g})$ & $(0.2641 \pm 0.003)$ \\
\hline Conductivity $(\mu \mathrm{S} / \mathrm{cm})$ & $(112.0 \pm 2)$ \\
\hline Humidity (\%) & $(1.48 \pm 0.16)$ \\
\hline The rate of ash (\%) & $(1.68 \pm 0.02)$ \\
\hline The percentage of organic matter (\%) & $(98.32 \pm 0.11)$ \\
\hline
\end{tabular}

Table 2: Physical and chemical properties of the apricot stones activated carbon (ASAC).

$$
R M S E=\sqrt{-\sum\left(q_{e, e \times p}-q_{e, c a l}\right)}
$$

Where, $\mathrm{q}_{\mathrm{e}(\exp )}(\mathrm{mg} / \mathrm{g})$ is the experimental value of uptake, $\mathrm{q}_{\mathrm{e}(\mathrm{cal})}$ the calculated value of uptake using a model $(\mathrm{mg} / \mathrm{g})$, and $\mathrm{N}$ the number of observations in the experiment (the number of data points). The small the RMSE values, the better the curve fitting [13].

The Fourier Transform Infrared (FTIR) spectrophotometer was used to identify the characteristic functional groups in the adsorption onto ASAC. $5 \mathrm{mg}$ of ASAC was mixed with dry spectroscopic KBr. The mixture was thoroughly mixed and pressed under a pressure of 4500 psi to form $\mathrm{KBr}$ thin disc. Then, the IR spectrum was plotted with a Perkin Elmer 2000 infrared spectrometer. The sample was scanned from $4000-400 \mathrm{~cm}^{-1}$ for 16 times to increase the signal to noise ratio.

The X-ray Diffraction (XRD) patterns of the Native Apricot Stone (NAS) and ASAC were obtained by using a Philips X-ray diffractometer of PW 1890 model. X-rays were generated from a tube with a copper target $(40 \mathrm{kV}, 40 \mathrm{~mA}, \lambda=1.54 \AA)$. The spectra were obtained with CONIT T-2T scan mode at $0.17 \mathrm{deg} / \mathrm{step}$ of step width and $8 \mathrm{deg} / \mathrm{min}$ of scan speed.

To observe the surface structure of the prepared ASAC before and after adsorption of the CB ions, scanning electron micrographs were taken with different resolutions by using a Scanning Electron Microscope (JOEL-5910).

The specific surface area (A) was determined on a Micromeritics ASAP2010M volumetric adsorption analyzer at $77 \mathrm{~K}$. The sample was degassed under vacuum at $573 \mathrm{~K}$ overnight before the measurement.

\section{Results and Discussion}

\section{Structural characterization by infrared spectroscopy analysis}

The Fourier Transform Infrared (FTIR) spectrum of ASAC is shown in Figure 1. The FTIR spectra of the adsorbent display a number of absorption peaks, indicating that many functional groups are present in the adsorbent. Peak positions are observed at 3436, 2929, 1732,1599 and $1508 \mathrm{~cm}^{-1}$. The band in the region between 3122-3680 $\mathrm{cm}^{-1}$ is related to the hydroxyl (-OH) groups (libber and intermolecular hydrogen band). The band at 2929 and $1508 \mathrm{~cm}^{-1}$ suggest the presence of $\left(-\mathrm{CH}_{2}\right)$ groups (symmetric and antisymetric) while the band in the region $1600-1665 \mathrm{~cm}^{-1}$ suggest the presence of groups $(\mathrm{C}-\mathrm{H},-\mathrm{C}=\mathrm{C}-$ and $\mathrm{C}=\mathrm{C}$ ). The peak at $1732 \mathrm{~cm}^{-1}$ is assigned to $\mathrm{C}=\mathrm{O}$ in the carboxylic groups. These results clearly indicate that functional groups including carboxylic and hydroxyl groups contribute to adsorption acid dye ions binding.

\section{Characterization of the prepared ASAC:}

The physical and chemical properties of ASAC and the elementary analysis are summarized in Table 2. The XRD patterns of the (NAS) and the prepared ASAC are shown in Figures $2 a$ and $2 b$, respectively. One can conclude from the ASAC pattern that there are no definite XRD peaks, suggesting that ASAC is mostly amorphous.

\section{Scanning Electron Microscopy (SEM) analysis of the prepared ASAC:}

SEM micrographs of ASAC before and after adsorption are pictured in Figures $3 \mathrm{a}$ and $3 \mathrm{~b}$ respectively. The prepared ASAC presents a microporous structure with different pore diameters. In addition, the ASAC surface seems to be rough and presents many protrusions before 


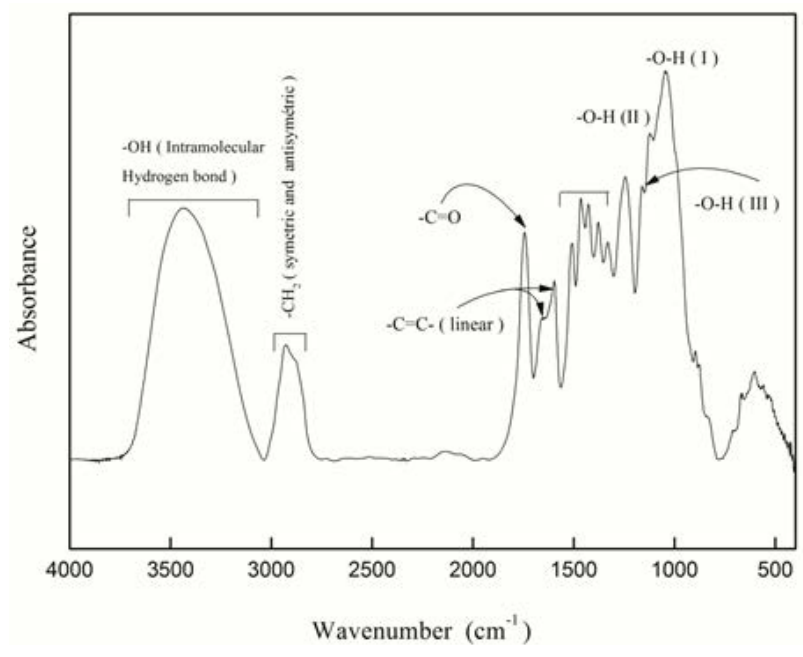

Figure 1: Spectrum of FTIR analysis from ASAC

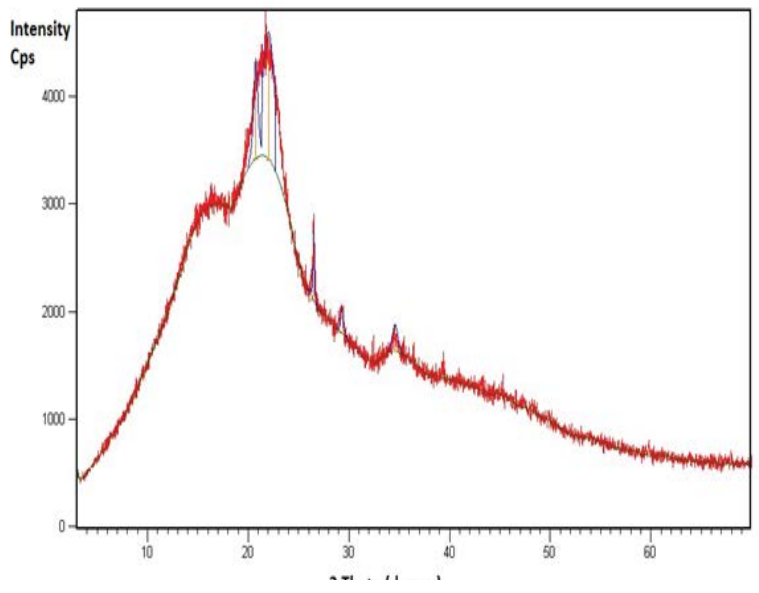

Figure 2a: X-ray patterns of the native apricot stone.

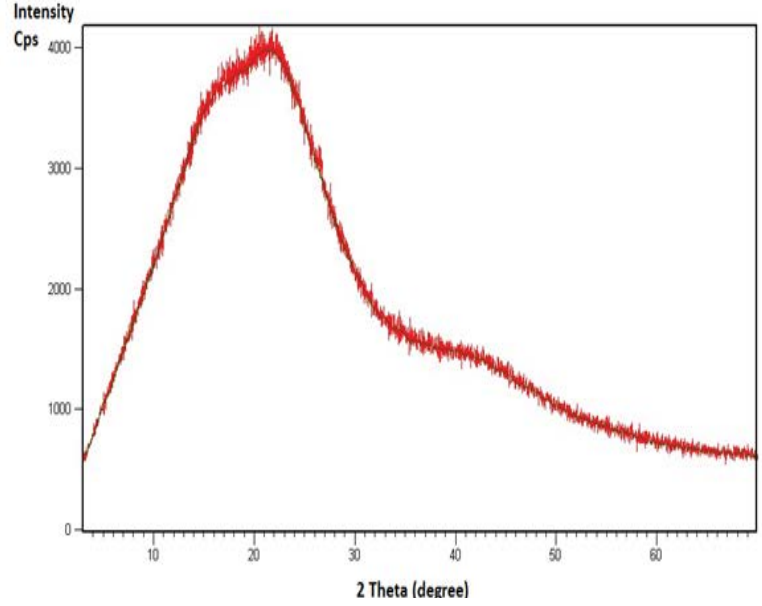

Figure 2b: X-ray patterns of the apricot stone activated carbon. adsorption. After adsorption, the ASAC morphology has changed and the surface has become smoother with less visible pores, indicating an adsorption on both the surface and within pores.

\section{Effect of analytical parameters}

Effect of ASAC size: In the first stage of batch adsorption experiments on ASAC, the effect of particle sizes on the acid dye adsorption by ASAC is examined. Significant variations in the uptake capacity and removal efficiency were observed at different particles sizes, indicating that the best performance is obtained with lower particle sizes $(315-800 \mu \mathrm{m})$. In general, smaller particles provide large surface area, resulting in high acid dye uptake capacity and removal efficiency. The range $(315-800 \mu \mathrm{m})$ is subsequently used in all adsorption experiments (Figure 4).

Effect of $\mathbf{p H}$ : The $\mathrm{pH}$ of the $\mathrm{CB}$ solution plays an important role in the adsorption process. It is evident that the percentage of acid dye removal increases consistently with decreasing $\mathrm{pH}$ (Figure 5). The effect of $\mathrm{pH}$ on the adsorption by ASAC can be explained on the basis of the point of zero charge $\mathrm{pH}(\mathrm{zpc})$, for which the adsorbent surface is neutral. The surface charge of the adsorbent is positive when the medium $\mathrm{pH}$ is under the $\mathrm{pH}(\mathrm{zpc})$ value and negative for $\mathrm{pH}$ over $\mathrm{pH}(\mathrm{zpc})$ [14]. Consequently due to electrostatic attraction, the adsorption of $\mathrm{CB}$ anions is favored. Indeed, the $\mathrm{CB}$ molecule presents differently charged states, corresponding to the amount of positive charges at the three nitrogen atoms present, while the two sulfonic acid groups are normally always negatively charged. Above $\mathrm{pH} 2$, only one nitrogen atom carries a positive charge and the dye molecule is a blue anion with an overall charge of -1 .

The $\mathrm{pH}(\mathrm{zpc}$ ) of ASAC is 7.05 (Figure 6) and the surface charge of ASAC is negative at higher $\mathrm{pH}$. As the $\mathrm{pH}$ decreases, the number of positively charged sites increases and favours the adsorption of $\mathrm{CB}$ anion by electrostatic attractions. Similar experimental details have been reported by Demirbas [15].

Effect of stirring speed: The effect of stirring speed on ASA adsorption is also investigated. The maximum adsorption is obtained for a speed of $300 \mathrm{rpm}$ (Figure 7). Such moderate speed gives the best homogeneity for the mixture suspension. At high speed, a vortex phenomenon occurs and the suspension is no longer homogenous which makes the adsorption of CB ions difficult.

Effect of contact time and initial concentration: The adsorption capacity of $\mathrm{CB}$ increases with time and attains a maximum value after $55 \mathrm{~min}$ and thereafter, it reaches a constant value indicating that no more $\mathrm{CB}$ ions are further removed from the solution. The equilibrium time works out to be $60 \mathrm{mn}$. Thus changing the initial concentration of acid dye from 10 to $100 \mathrm{mg} / \mathrm{L}$, the adsorbed amount increases from 8.09 to $66.17 \mathrm{mg} / \mathrm{g}$ (Figure 8). This may be attributed to an increase in the driving force of the concentrations gradient with increasing the initial acid dye concentration in order to overcome the mass transfer resistance of $\mathrm{CB}$ ions between the aqueous and solid phases.

Effect of adsorbent dosage: For the first stage of batch adsorption experiments on ASAC, the effect of adsorbent dosage on the acid dye adsorption by ASAC is examined. Significant variations in the uptake capacity and removal efficiency are observed at different adsorbent dosages $(1$ to $7 \mathrm{~g} / \mathrm{L})$ indicate that the best performance is obtained with an adsorbent dosage of $7 \mathrm{~g} / \mathrm{L}$ (Figure 9), this result was expected because the removal efficiency is generally increased by the fact that more mass available, more the contact surface offered to the adsorption. Moreover, the higher dose of adsorbent in the solution, the greater availability of 
Citation: Moussa A, Abdelhamid C, Samia K, Tounsia A, Mohamed T (2015) Kinetic and Equilibrium Studies of Coomassie Blue G-250 Adsorption on Apricot Stone Activated Carbon. J Environ Anal Toxicol 5: 264. doi:10.4172/2161-0525.1000264

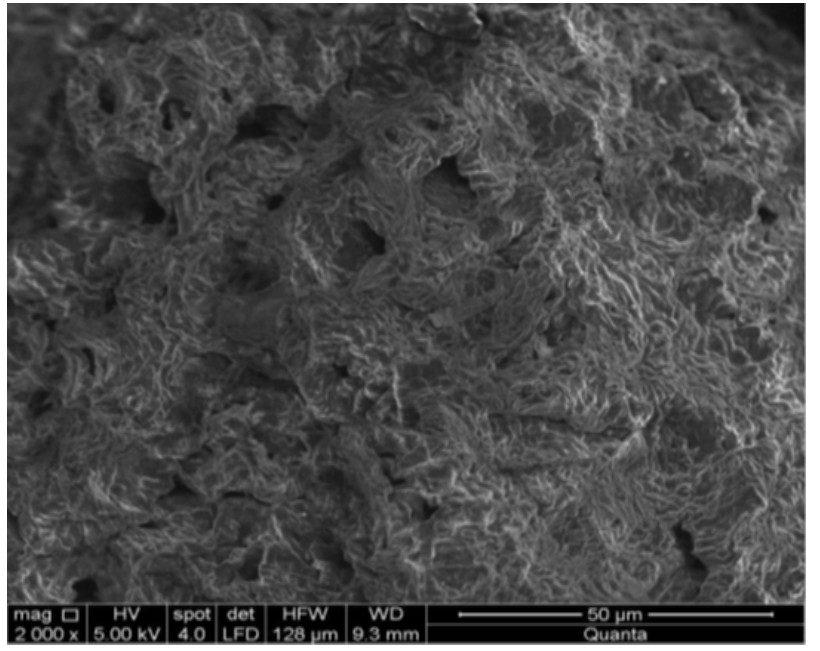

Figure 3a: Scanning electron micrographs of the ASAC before adsorption.

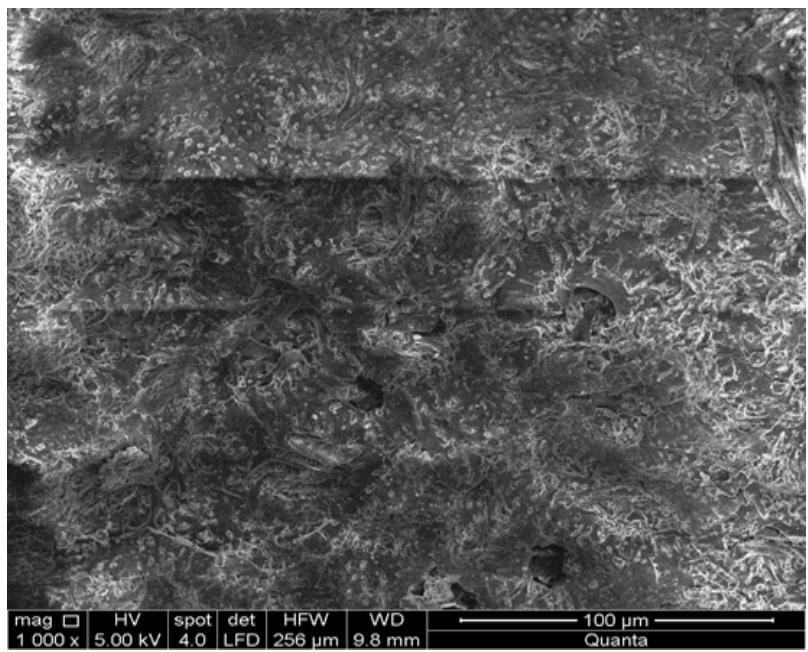

Figure $3 b$ : Scanning electron micrographs of the ASAC after adsorption.

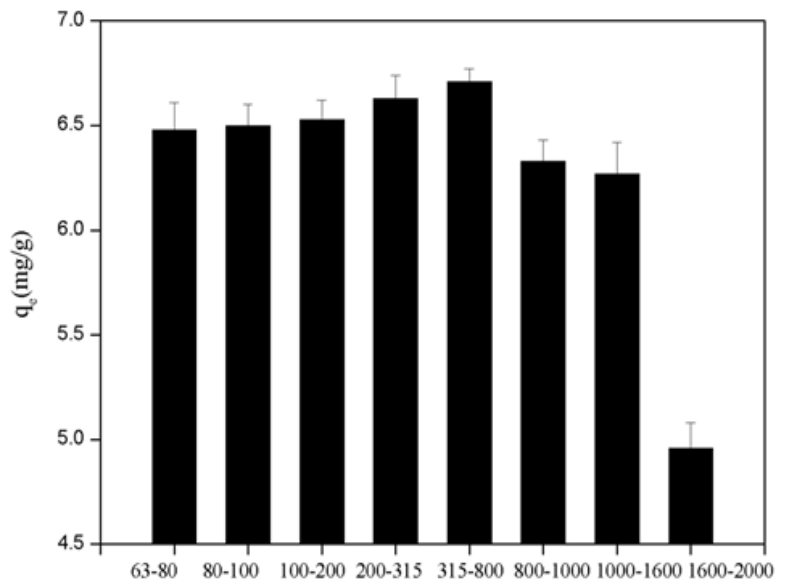

Particule size $(\mu \mathrm{m})$

Figure 4: Effect of particle size on the $\mathrm{CB}$ adsorption efficiency $(\mathrm{T}=20$ ${ }^{\circ} \mathrm{C}, \mathrm{C}_{0}=20 \mathrm{mg} / \mathrm{L}, \mathrm{V}=10 \mathrm{~mL}$, contact time $=90 \mathrm{mn}$, stirring speed $=300$ rpm).

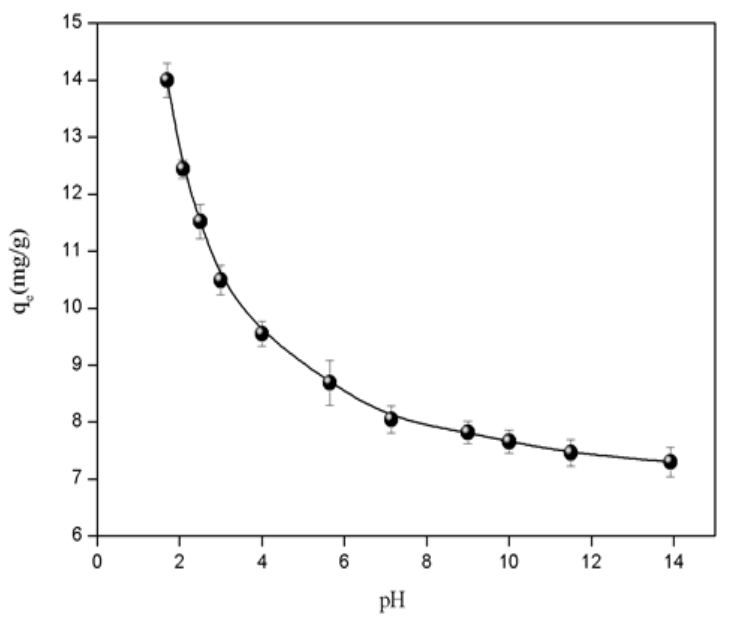

Figure 5: Effect of $\mathrm{pH}$ on the $\mathrm{CB}$ adsorption efficiency $\left(\mathrm{T}=20^{\circ} \mathrm{C}, \mathrm{C}=20\right.$ $\mathrm{mg} / \mathrm{L}, \mathrm{V}=10 \mathrm{~mL}$, contact time $=90 \mathrm{mn}$, stirring speed $=300 \mathrm{rpm}$ ).

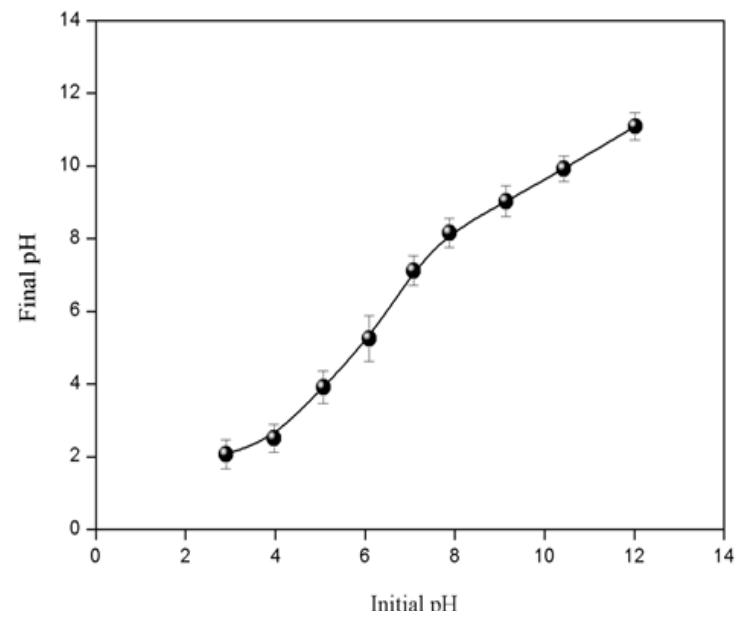

Figure 6: $\mathrm{pH}$ of the point of zero charge pHpzc of the ASAC.

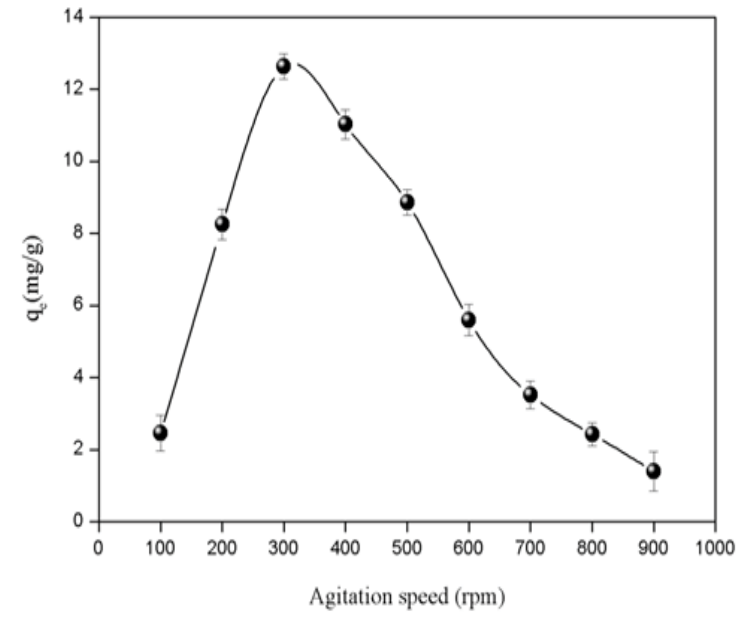

Figure 7: Effect of stirring speed on the $\mathrm{CB}$ dye adsorption capacity $\left(\mathrm{C}_{0}=\right.$ $20 \mathrm{mg} / \mathrm{L}, \mathrm{T}=293 \mathrm{~K}, \mathrm{pH}=2$, Particle size : [315-800 $\mu \mathrm{m}]$ ). 


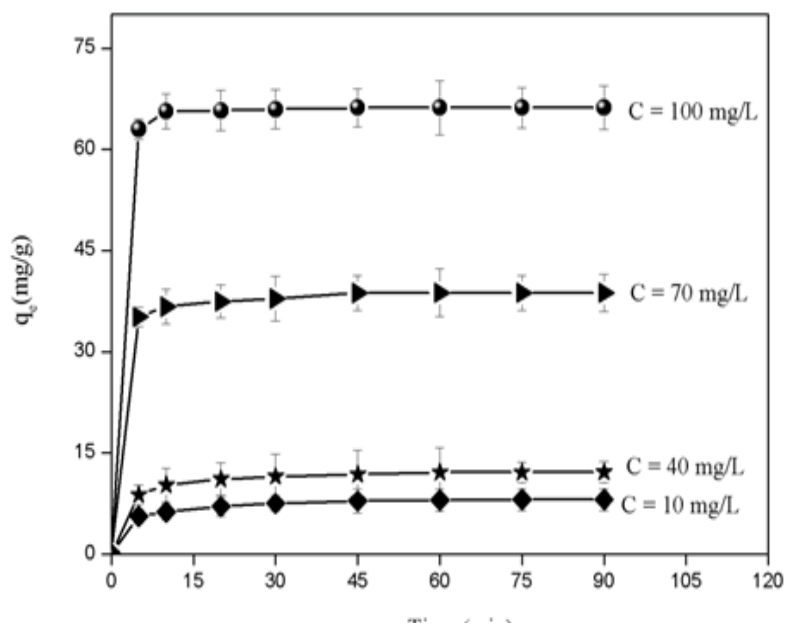

Figure 8: Effect of the contact time on the adsorption of CB onto ASAC for different initial concentrations (Stirring speed $=300 \mathrm{rpm}$, absorbent dosage $=1.5 \mathrm{~g} / \mathrm{L}, \mathrm{T}=293 \mathrm{~K}, \mathrm{pH}=2$ )

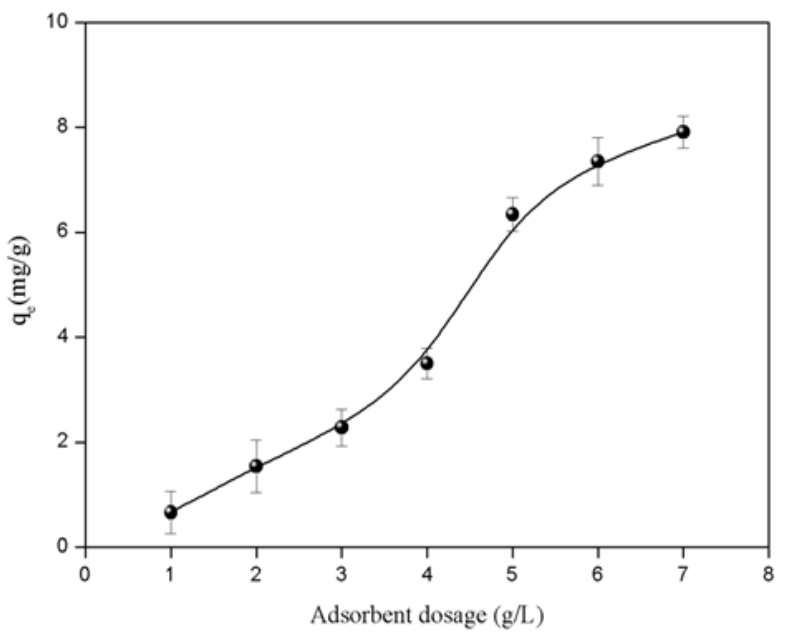

Figure 9: Effect of adsorption dosage on the $\mathrm{CB}$ dye adsorption capacity ( $\mathrm{C}_{0}=20 \mathrm{mg} / \mathrm{L}, \mathrm{pH}=2, \mathrm{~T}=293 \mathrm{~K}$, Particle size : [315-800 $\left.\mu \mathrm{m}\right]$ ).

exchangeable sites for the ions, i.e. more active sites are available for binding of CB ions. Our results are qualitatively in a good agreement with those found in the literatures. This result is subsequently used in all isotherms adsorption experiments.

Adsorption isotherms: The shape of the isotherms is the first experimental tool to diagnose the nature of a specific adsorption phenomenon. The isotherms have been classified according to Giles et al. [16] in four main groups: L, S, H, and C. According to the above classification, the isotherms of ASAC at different temperatures (22.5 ${ }^{\circ} \mathrm{C}$ and $50{ }^{\circ} \mathrm{C}$ ) display L type curve (Figure 10). The initial part of the $\mathrm{L}$ curve indicates a small interaction between acid dye and the carrier at low concentrations. However, as the concentration in the liquid phase increases, the adsorption occurs more readily. This behaviour is due to a synergistic effect, with the adsorbed molecules facilitating the adsorption of additional molecules as a result of attractive interaction adsorbate-adsorbate. The equilibrium relationships between the adsorbent and adsorbate are described by the Langmuir [17] and the Freundlich models [18] and the applicability to the adsorption study done is compared by evaluating the statistic RMSE values. The linear forms of the Langmuir and Freundlich isotherms are represented by the following equations (B1) and (B2):

$$
\frac{1}{q_{e}}=\frac{1}{q_{\max }} \cdot \frac{1}{q_{\max } k_{L} C_{e}}
$$

Where $\mathrm{C}_{e}$ is the equilibrium concentration $(\mathrm{mg} / \mathrm{L}), \mathrm{q}_{\text {max }}$ the monolayer adsorption capacity $\left(\mathrm{mg} / \mathrm{g}\right.$ ) and $\mathrm{K}_{\mathrm{L}}$ the constant related to the free adsorption energy (Langmuir constant, $\mathrm{L} / \mathrm{mg}$ ).

$$
L n q_{e}=\operatorname{Ln} K_{F}+\frac{1}{n} \cdot \operatorname{LnCe}
$$

The constant $\mathrm{K}_{\mathrm{F}}$ indicates the adsorption capacity of the adsorbent $(\mathrm{L} / \mathrm{g})$ and $\mathrm{n}$ is an empirical constant related to the magnitude of the adsorption driving force. The linearized forms of the Langmuir and Freundlich isotherms of $\mathrm{CB}$ for two temperatures $\left(22.5\right.$ and $\left.50{ }^{\circ} \mathrm{C}\right)$ and the theoretical parameters along with the regression coefficients are listed in Table 3. The smaller RMSE values obtained for the Freundlich model indicate a better curve fitting. The favourable nature of the adsorption can be expressed in terms of dimensionless separation factor of equilibrium parameter, which is defined by equation (B3) [19]:

$$
R_{L}=\frac{1}{1+K_{L} \cdot C_{0}}
$$

Where $\mathrm{K}_{\mathrm{L}}$ is the Langmuir constant and $\mathrm{C}_{\mathrm{o}}$ the initial concentration of the adsorbate in solution. The values of $\mathrm{R}_{\mathrm{L}}$ indicates the type of isotherm: irreversible $\left(\mathrm{R}_{\mathrm{L}}=0\right)$, favourable $\left(0<\mathrm{R}_{\mathrm{L}}<1\right)$, linear $\left(\mathrm{R}_{\mathrm{L}}=1\right)$ or unfavourable $\left(R_{L}>1\right)$. In this study, the $R_{L}$ values are less than 1 , confirming that the adsorption process is favoured in both the cases as well as the applicability of Langmuir isotherm.

Adsorption kinetics: The kinetic study is important for the adsorption process, it describes the uptake rate of adsorbate and controls the residual time of the whole adsorption process. Two kinetic models namely the pseudo first order and pseudo second-order are selected in this study to describe the adsorption. The pseudo first order equation [20] is given in equation $(\mathrm{C} 1)$ :

$$
\log \left(q_{e}-q_{t}\right)=\log q_{e}-\frac{K_{1}}{2.303} . t
$$

The pseudo second order model $[21,22]$ is expressed by the equation (C2):

$$
\frac{t}{q_{t}}=\frac{1}{K_{2} \cdot q_{e}^{2}}+\frac{1}{q_{e}} \cdot t
$$

Where $\mathrm{q}_{\mathrm{t}}(\mathrm{mg} / \mathrm{g})$ is the amount of metal adsorbed on the adsorbent at various times $\mathrm{t}(\mathrm{min}), \mathrm{K}_{1}$ the rate constant of the pseudofirst order kinetic $\left(\mathrm{min}^{-1}\right), \mathrm{K}_{2}$ the rate constant of the pseudo-second order kinetic ( $\mathrm{g} / \mathrm{mg} \mathrm{min})$.

The rate constants, predicted uptakes and the correlation coefficients for ASAC are summarized in Table 4. For the pseudo-first order kinetic, the experimental data deviate greatly from linearity. This was evidenced by the low values of $\mathrm{q}_{e}$ and correlation coefficients. Therefore, the pseudo-first order model is inapplicable to this system. The correlation coefficient and $\mathrm{q}_{\mathrm{e}}$ 'cal of the pseudo-second order kinetic model are in good agreement with the experimental results (Table 4).

Effect of temperature: The Activation Energy (Ea) of acid dye BC adsorption onto ASAC is calculated by from the Arrhenius equation (D1) [23].

$$
\log K=-\frac{E_{a}}{R \cdot T}+c
$$

The rate constant $\mathrm{k}$ (Table 5) increases with increasing the 
Citation: Moussa A, Abdelhamid C, Samia K, Tounsia A, Mohamed T (2015) Kinetic and Equilibrium Studies of Coomassie Blue G-250 Adsorption on Apricot Stone Activated Carbon. J Environ Anal Toxicol 5: 264. doi:10.4172/2161-0525.1000264

Page 6 of 8

temperature, indicating that the adsorption is favored at high temperature where $\mathrm{R}$ is the gas constant $(8.314 \mathrm{~J} / \mathrm{K} . \mathrm{mol})$, and $\mathrm{T}$ the temperature $(\mathrm{K})$. The activation energy $(66.161 \mathrm{~kJ} / \mathrm{mol})$ is computed from the slope of the plot of lnk versus 1/T (Figure 11). The thermodynamic parameters were calculated in the range temperature studies and given in Table 6.

Performance of the prepared ASAC: In order to have an idea about the efficiency of the prepared ASAC, a comparison of acid dye adsorption of this work and other relevant studies is reported in Table 7. The adsorption capacity of the adsorbent $\mathrm{q}_{\max }$ is the parameter used for the comparison. One can conclude that the value of $\mathrm{q}_{\max }$ is in good agreement with those of most previous works, suggesting that $\mathrm{CB}$ could be easily adsorbed on ASAC used in this work. This indicates that the apricot stone, very abundant in Algeria, is a cheap and effective adsorbent for the $\mathrm{CB}$.

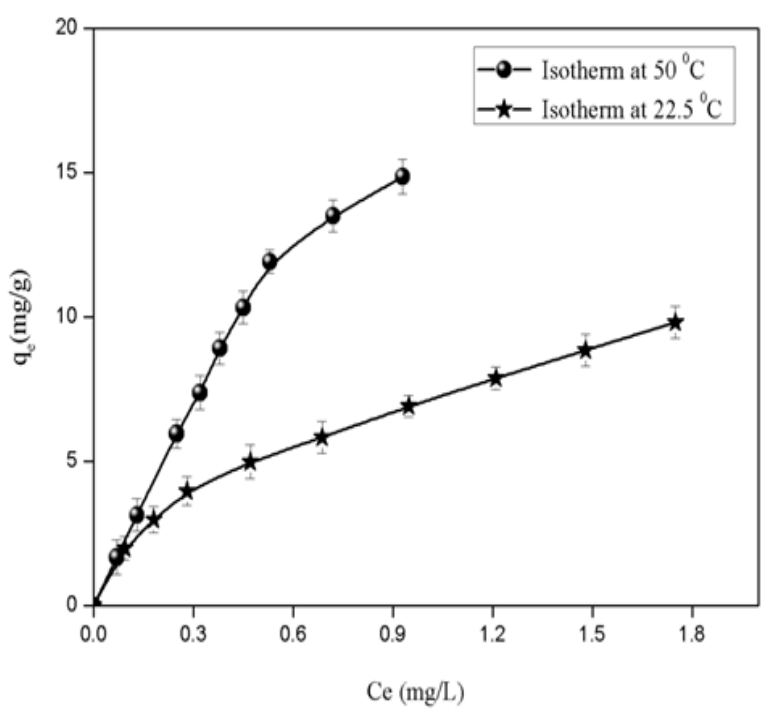

Figure 10: Adsorption isotherms of CB by ASAC

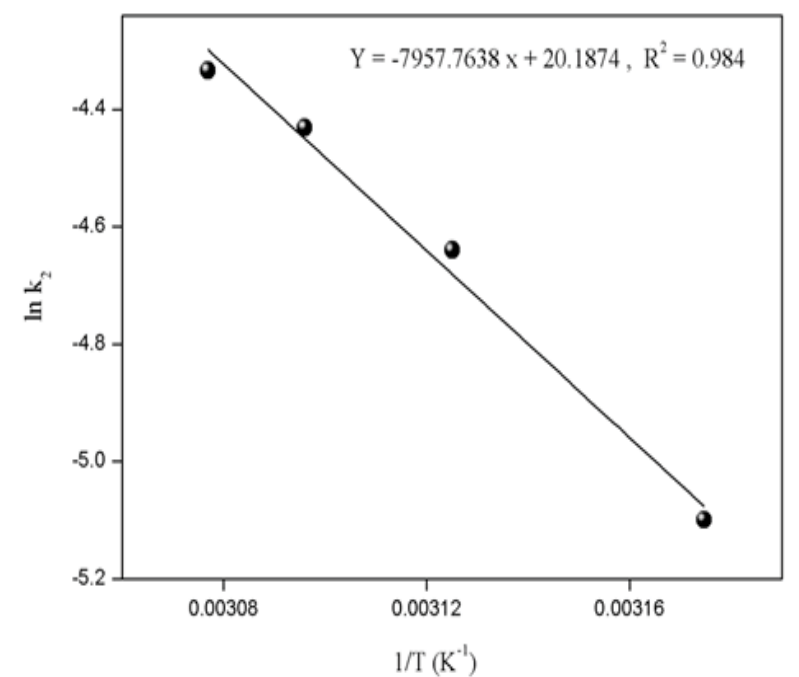

Figure 11: A plot of In $k 2$ against 1/T for the adsorption of $C B$ onto ASAC

\begin{tabular}{|c|c|c|c|c|c|c|c|}
\hline \multicolumn{4}{|l|}{$\mathrm{T}=22.5^{\circ} \mathrm{C}$} & \multicolumn{4}{|l|}{$\mathrm{T}=50^{\circ} \mathrm{C}$} \\
\hline \multicolumn{2}{|l|}{ Langmuir } & \multicolumn{2}{|c|}{ Freundlich } & \multicolumn{2}{|l|}{ Langmuir } & \multicolumn{2}{|c|}{ Freundlich } \\
\hline \multicolumn{2}{|l|}{$/ \mathrm{Ce}=\mathrm{f}(1 / \mathrm{qe})$} & \multicolumn{2}{|c|}{ Inge $=\mathrm{f}(\ln \mathrm{Ce})$} & \multicolumn{2}{|c|}{$1 / \mathrm{Ce}=f(1 / \mathrm{qe})$} & \multicolumn{2}{|c|}{ Inqe $=\mathrm{f}(\ln \mathrm{Ce})$} \\
\hline $\mathrm{Q}_{\max }(\mathrm{mg} / \mathrm{g})$ & 10.09 & $1 / n$ & 0.52 & $\mathrm{Q}_{\max }(\mathrm{mg} / \mathrm{g})$ & 98.022 & $1 / n$ & 0.52 \\
\hline $\mathrm{K}_{\mathrm{L}}(\mathrm{L} / \mathrm{mg})$ & 2.46 & $\mathrm{~K}_{\mathrm{F}}(\mathrm{mg} / \mathrm{g})$ & 7.25 & $K_{L}(L / m g)$ & 0.253 & $\begin{array}{l}1 / \mathrm{n} \\
\mathrm{K}_{\mathrm{F}}(\mathrm{mg} / \mathrm{g})\end{array}$ & $\begin{array}{l}0.52 \\
19\end{array}$ \\
\hline RMSE & 0.45 & RMSE: & 0.014 & RMSE & 1.93 & $\begin{array}{l}\mathrm{R}^{2} \\
\mathrm{RMSE}\end{array}$ & $\begin{array}{l}0.96 \\
1.34\end{array}$ \\
\hline
\end{tabular}

Table 3: Sorption isotherm coefficients of Langmuir and Freundlich models

\begin{tabular}{|c|c|c|c|c|c|c|c|c|c|}
\hline \multicolumn{4}{|c|}{ Pseudo- First order Kinetic } & \multicolumn{6}{|c|}{ Pseudo- second order Kinetic } \\
\hline$(\mathrm{mg} / \mathrm{L})$ & $\begin{array}{l}Q_{\text {exp }} \\
(\mathrm{mg} / \mathrm{q})\end{array}$ & $\begin{array}{l}Q_{\text {cal }} \\
(\mathrm{mg} / \mathrm{q})\end{array}$ & $\begin{array}{l}\mathrm{K}_{1} \\
\left(\mathrm{mn}^{-1}\right)\end{array}$ & $\mathrm{R}^{2}$ & & $\begin{array}{l}Q_{\text {cal }} \\
(\mathrm{mg} / \mathrm{q})\end{array}$ & $\begin{array}{l}\mathrm{K}_{2} \\
\text { (g/mgmn) }\end{array}$ & $\mathrm{R}^{2}$ & RMSE \\
\hline 10 & 8.09 & 3.376 & 0.0608 & 0.99 & 0.112 & 8.3890 & 0.0389 & 0.99 & 0.32 \\
\hline 40 & 12.14 & 3.645 & 0.0566 & 0.94 & 10.26 & 12.583 & 0.0318 & 0.99 & 0.45 \\
\hline 70 & 38.72 & 4.036 & 0.0562 & 0.94 & 34.12 & 39.200 & 0.3644 & 0.99 & 0.23 \\
\hline 100 & 66.18 & 0.630 & 0.0022 & 0.79 & 73.23 & 68.483 & 0.0170 & 0.99 & 0.11 \\
\hline
\end{tabular}

Table 4: Kinetic parameters for adsorption of CB ions onto ASAC

\begin{tabular}{|cc|cc|l|}
\hline $\mathbf{T}\left({ }^{\circ} \mathbf{C}\right)$ & $\mathbf{Q e}(\mathbf{m g} / \mathbf{g})$ & $\mathbf{K}_{\mathbf{2}}(\mathbf{g} / \mathbf{m g} \cdot \mathbf{m n})$ & $\mathbf{R}^{\mathbf{2}}$ & $\mathbf{R M S E}$ \\
\hline 42 & 10.18 & $6.1010^{-3}$ & 0.998 & 1.01 \\
47 & 11.63 & $9.6410^{-3}$ & 0.999 & 0.09 \\
50 & 13.49 & $11.9010^{-3}$ & 0.999 & 0.22 \\
52 & 17.58 & $13.1210^{-3}$ & 0.999 & 0.12 \\
\hline
\end{tabular}

Table 5: The rate constant $k_{2}$ at different temperatures

\begin{tabular}{|c|c|c|c|c|}
\hline $\mathbf{T}(\mathbf{K})$ & $\mathbf{K}_{\mathrm{L}}(\mathbf{L} / \mathbf{m g})$ & $\left.\mathbf{\Delta} \mathbf{G}^{\circ} \mathbf{~} \mathbf{J} / \mathbf{m o l}\right)$ & $\left.\boldsymbol{\Delta} \mathbf{H}^{\circ} \mathbf{( k J / m o l}\right)$ & $\boldsymbol{\Delta} \mathbf{S}^{\circ}(\mathbf{J} / \mathbf{m o l} . \mathbf{K})$ \\
\hline 295.5 & 2.55 & -19.27 & -55.088 & 121.209 \\
329 & 0.26 & -15.21 & & \\
\hline
\end{tabular}

Table 6: Thermodynamic parameters for the CB adsorption on ASAC

\begin{tabular}{|c|c|c|c|}
\hline Days & Adsorbents & $Q(\mathrm{mg} / \mathrm{g})$ & References \\
\hline $\begin{array}{l}\text { CBB } \\
\text { CBB } \\
\text { CBB }\end{array}$ & $\begin{array}{l}\text { Apricot Stones Activated Carbon } \\
\text { Coir Pith } \\
\text { Wheat bran as a low-cost adsorbent. }\end{array}$ & $\begin{array}{l}98.021 \\
31.847 \\
6.4100\end{array}$ & $\begin{array}{l}\text { This study } \\
{[24]} \\
{[24]}\end{array}$ \\
\hline $\begin{array}{l}\text { Basic Yellow } \\
\text { Methylene Blue } \\
\text { Acid Fuchsin } \\
\text { Acid Blue } 45 \\
\text { Methylene Bleu }\end{array}$ & $\begin{array}{l}\text { Cranular A C produced from Coffee Ground } \\
\text { Bamboo Dust Carbon } \\
\text { Sodium Motmorillonite } \\
\text { Activated Carbon cloth } \\
\text { Grounde Palm Kernel coat }\end{array}$ & $\begin{array}{l}10.000 \\
143.20 \\
93.240 \\
65.460 \\
277.77\end{array}$ & $\begin{array}{l}{[25]} \\
{[26]} \\
{[27]} \\
{[28]} \\
{[29]}\end{array}$ \\
\hline $\begin{array}{l}\text { Jaune Benzanyl } \\
\text { Jaune Benzanyl }\end{array}$ & $\begin{array}{l}\text { Bentonite } \\
\text { Kaolin }\end{array}$ & $\begin{array}{l}40.50 \\
30.60\end{array}$ & $\begin{array}{l}{[30]} \\
{[30]}\end{array}$ \\
\hline Methylene Blue & $\begin{array}{l}T=290 \mathrm{~K} \\
\mathrm{~T}=300 \mathrm{~K} \\
\mathrm{~T}=310 \mathrm{~K}\end{array}$ & $\begin{array}{l}103.62 \\
109.31 \\
119.70\end{array}$ & $\begin{array}{l}{[31]} \\
{[31]} \\
{[31]}\end{array}$ \\
\hline $\begin{array}{l}\text { Vert de methyl } \\
\text { Astrazon Yelow } \\
\text { Methylene Blue }\end{array}$ & $\begin{array}{l}\text { Charbon actif } \\
\text { Apricot Stone Activated.Carbon } \\
\text { A.C prepared from strychnos potatorium seed }\end{array}$ & $\begin{array}{l}30.700 \\
211.23 \\
100.00\end{array}$ & $\begin{array}{l}{[32]} \\
{[33]} \\
{[34]}\end{array}$ \\
\hline $\begin{array}{l}\text { Methylene Blue } \\
\text { Methylene Blue } \\
\text { Methylene Blue } \\
\text { Methylene Blue } \\
\text { Methylene Blue }\end{array}$ & $\begin{array}{l}\text { Activated carbon (coconut shell fibbers) } \\
\text { Activated carbon (olive stones) } \\
\text { Coton Wast } \\
\text { DatePpits } \\
\text { Zeolite }\end{array}$ & $\begin{array}{l}19.59 \\
303.0 \\
240.0 \\
80.30 \\
53.10\end{array}$ & $\begin{array}{l}{[35]} \\
{[36]} \\
{[37]} \\
{[38]} \\
{[39]}\end{array}$ \\
\hline $\begin{array}{l}\text { Methyl Orange } \\
\text { Rouge Congo } \\
\text { Methylene Blue } \\
\text { Rouge Congo } \\
\text { Basic Blue } 3\end{array}$ & $\begin{array}{l}\text { Camel Thorn Plant } \\
\text { Charbon Actif } \\
\text { Charbon Actif } \\
\text { Lignin-Based Activated Carbons } \\
\text { A. Carbon Derived from Agricultural Waste }\end{array}$ & $\begin{array}{l}20.830 \\
35.210 \\
194.73 \\
812.50 \\
227.27\end{array}$ & $\begin{array}{l}{[40]} \\
{[41]} \\
{[41]} \\
{[42]} \\
{[43]}\end{array}$ \\
\hline
\end{tabular}

Table 7: Comparison of ASAC performances with precursors from previous studies 
Citation: Moussa A, Abdelhamid C, Samia K, Tounsia A, Mohamed T (2015) Kinetic and Equilibrium Studies of Coomassie Blue G-250 Adsorption on Apricot Stone Activated Carbon. J Environ Anal Toxicol 5: 264. doi:10.4172/2161-0525.1000264

\section{Conclusions}

This study has shown that activated carbon prepared from apricot stone can be employed as effective adsorbent for the removal of Coomassie Blue from aqueous solution. The Freundlich isotherm model provided a better fit of the equilibrium adsorption data than the Langmuir isotherm one. It gave a maximum adsorption capacity of $10.04 \mathrm{mg} / \mathrm{g}$ at temperature $22.5^{\circ} \mathrm{C}$ which increased up to $98.04 \mathrm{mg} / \mathrm{g}$ at $50^{\circ} \mathrm{C}$ at $\mathrm{pH} \sim 2$. The pseudo-second order model proved the best description of the kinetic data. The negative values of $\Delta \mathrm{G}$ and $\Delta \mathrm{H}$ indicate that the adsorption of $\mathrm{CB}$ onto ASAC is spontaneous and exothermic over the studied range of temperatures. The positive value of $\Delta \mathrm{S}$ state clearly that the randomness increased at the solid-solution interface during the $\mathrm{CB}$ adsorption onto ASAC, indicating that some structural exchange may occur among the active sites of the adsorbent and the ions. The activation energy and the rate constant increase with increasing temperature, indicating that adsorption is favored at high temperature. The adsorption of CB ions by ASAC follows a pseudosecond order kinetic model, which relies on the assumption that chemisorptions may be the rate-limiting step. In chemisorption, the $\mathrm{CB}$ ions are attached to the adsorbent surface by forming a chemical bond and tend to find sites that maximize their coordination number with the surface. This study in tiny batch gave rise to encouraging result, and we wish to achieve the adsorption tests in column mode under the conditions applicable to the treatment of industrial effluents and the present investigation showed that ASAC is a potentially useful adsorbent for the metals, acid and basic dyes.

\section{References}

1. Hameed BH, Ahmad AL, Latiff KNA (2007) Adsorption of basic dye (methylene blue) onto activated carbon prepared from rattan sawdust. Dyes Pigments 75 : $143-149$.

2. Hameed BH, Daud FBM (2008) Adsorption studies of basic dye on activated carbon derived from agricultural waste: Hevea brasiliensis seed coat. Chem Eng J 139: 48-55.

3. Waranusantigul P, Pokethitiyook P, Kruatrachue M, Upatham ES (2003) Kinetics of basic dye (methylene blue) biosorption by giant duckweed (Spirodela polyrrhiza). Environ Pollut 125: 385-392.

4. Robinson T, McMullan G, Marchant R, Nigam P (2001) Remediation of dyes in textile effluent: a critical review on current treatment technologies with a proposed alternative. Bioresour Technol 77: 247-255.

5. Chan LS, Cheung WH, Allen SJ, McKay G (2012) Error Analysis of Adsorption Isotherm Models for Acid Dyes onto Bamboo Derived Activated Carbon. Chin J Chem Eng 20: 535-542.

6. Auta M, Hameed BH (2011). Preparation of waste tea activated carbon using potassium acetate as an activating agent for adsorption of Acid Blue 25 dye. Chem Eng J 171: 502-509.

7. Valix M, Cheung WH, McKay G (2004) Preparation of activated carbon using low temperature carbonisation and physical activation of high ash raw bagasse for acid dye adsorption. Chemosphere 56: 493-501.

8. Walker GM, Hansen L, Hanna JA, Allen SJ (2003) Kinetics of a reactive dye adsorption onto dolomitic sorbents, Water Res 37: 2081-2089.

9. Theydan SK, Ahmed M J (2012). Optimization of preparation conditions for activated carbons from date stones using response surface methodology. Powder Technol 224: 101-108.

10. Ata S, Din MI, Rasool A, Qasim I, UIMohsin I (2012) Equilibrium, Thermodynamics, and Kinetic Sorption Studies for the Removal of Coomassie Brilliant Blue on Wheat Bran as a Low-Cost Adsorbent. J Anal Methods Chem 2012: 8.

11. Vargas AMM, Cazetta AL, Martins AC, Moraes JCG, Garcia EE, et al. (2012) Kinetic and equilibrium studies: Adsorption of food dyes Acid Yellow 6, Acid Yellow 23, and Acid Red 18 on activated carbon from flamboyant pods. Chem Eng J 181-182: 243-250.
12. Carlsson N, Kitts CC, Åkerman B (2012) Spectroscopic characterization of Coomassie blue and its binding to amyloid fibrils. Anal Biochem 420: 33-40.

13. Abbas M, Kaddour S, Trari M (2014) Kinetic and equilibrium studies of cobalt adsorption on apricot stone activated carbon. Journal of Ind and Eng Chem 20: $745-751$.

14. Cerovic LJS, Milonjic SK, Todorovic MB, Trtanj MI, Pogozhev YS, et al. (2007) Point of zero charge of different carbides. Colsurfs Physicochemistry Enginneering Aspects 297: 1-6.

15. Demirbas E (2003) Adsorption of cobalt (II) ions from aqueous solution onto activated carbon prepared from hezelmut shells, Adsor. Scien. and Technology 21: $951-963$

16. Giles CH, MacEwan TH, Nakhwa SN, Smith D (1960) Studies in Adsorption. Part XI. A System of Classification of Solution Adsorption Isotherms, and its Use in Diagnosis of Adsorption Mechanisms and in Measurement of Specific Surface Areas of Solids. J Chem Soc 10: 3973-3993.

17. Langmuir I (1918) The adsorption of gases on plane surfaces of glass, mica and platinum. J Am Chem Soc 40: 1361-1403.

18. Freundlich HMF (1906) Over the adsorption in solution. J Phys Chem 57: 385 470

19. Hall KR, Eagleton LC, Acrivos A, Vermeulen T (1966) Pore-and solid-diffusion kinetics in fixed-bedadsorption under constant-pattern conditions. Ind Eng Chem Fundam 5: 212-223

20. Lagergren $S$ (1898) About the theory of so-called adsorption of soluble substances. K Sven Ventensskapsakad Handlingar Band 24: 1-39.

21. Ho YS, Mc Kay G (2000) The Kinetics of sorption of divalent metal ions onto sphagnum moss peat. Water Res 34: 735-742.

22. Ho YS, Mc Kay G (1999) Pseudo-second order model for sorption processes. Press Biochemistry 34: 451-465.

23. Tassist A, Lounici H, Abdi N, Mameri N (2010) Equilibrium, kinetic and thermodynamic studies on aluminum biosorption by a mycelial biomass (Streptomyces rimosus). J Hazard Mater 183: 35-43

24. Naveen Prasad R, Viswanathan S, Renuka Devi J, Johanna Rajkumar, Parthasarathy N (2008) Kinetics and Equilibrium Studies on Biosorption of CBB by Coir Pith. American-Eurasian J Scientific Res 3: 123-127.

25. Namane A, Mekarzia A, Benrachedib K, Belhaneche-Bensemra N, Hellal A (2005) Determination of the adsorption capacity of activated carbon madefrom coffee grounds by chemical activation with $\mathrm{ZnCl}_{2}$ and $\mathrm{H}_{3} \mathrm{PO}_{4}$, J Hazard Mater B119: 189-194.

26. Kannan N, Sundaram MM (2001) Kinetics and mechanism of removal of methylene blue by adsorption on various carbons-a comparative study. Dyes Pigments 51: 25-40.

27. Elsherbiny AS (2013). Adsorption kinetics and mechanism of acid dye onto montmorillonite from aqueous solutions: Stopped-flow measurements. App Clay Sci 83/84: 56-62.

28. Hoda N, Bayram E, Ayranci E (2006) Kinetic and equilibrium studies on the removal of acid dyes from aqueous solutions by adsorption onto activated carbon cloth. J Hazard Mater B137: 344-351.

29. Oladoja NA, Aboluwoye CO, Oladimeji YB, et al. (2008) Kinetic and isotherm studies of MB adsorption onto ground palm kernel coat. Turkish J Eng Env Scie 32: 303-312.

30. Benguella B, yacouta Nour A (2009). Elimination des colorants acides en solution aqueuse par la bentonite et le Kaolin CR chimie: 1-10

31. Hardryari Z (2010). Experimental stady of methylene bleu adfsorption from aqueous solution onto carbon nano tube. I $\mathrm{J}$ of water resources and environmental Eng ineering 2: 16-28.

32. Baghriche O, Djebbar K, Sehili T (2008) Etude de l'adsorption d'un colorant cationique (vert de methyl) sur un charbon actif en milieu aqueux. Science et technologie A $27 \vee$ B: 57-62.

33. Demirbas E, kobay M, Sulak MT (2008) Adsorption kinetics of a basic dye (Astrazon Yelow $7 \mathrm{GL}$ ) from aqueous solutions onto apricot stone activated carbon Biores. Technology 99: 5368-5373.

34. Antony Joseph MJ, Xavier N (2012) Equilibrium isotherm studies of MB from aqueous solution unto activated carbon prepared from strychnos potatorium seed Inter. J Appl Biology and Pharma Tech 3: 27-31. 
Citation: Moussa A, Abdelhamid C, Samia K, Tounsia A, Mohamed T (2015) Kinetic and Equilibrium Studies of Coomassie Blue G-250 Adsorption on Apricot Stone Activated Carbon. J Environ Anal Toxicol 5: 264. doi:10.4172/2161-0525.1000264

35. Faust GT, Hathaway JC, Millot GA (1959) Restudy of stevensite and allied minerals. Am Miner 44: 342-370.

36. Voudrias E, Fytianos K, Bozani E (2002) Sorption-desorption isotherms of dyes from aqueous solutions and wastewaters with different sorbent materials. Global Nest: the Int J 4: 75-83.

37. Weber TW, Chackravorti RK, (1974) Pore and solid diffusion models for fixed bed adsorbers. Amer Inst Chem Eng J 20: 228-238.

38. Suteu D, Bilba D (2005) Equilibrium and Kinetic Study of Reactive Dye Brilliant Red HE-3B Adsorption by Activated Charcoal. Acta Chim Slov 52: 73-79.

39. Stephenson RJ, Sheldon JB (1996) Coagulation and Precipitation of a Mechanical Pulping Effluent: 1. Removal of Carbon and Turbidity. Water Res 30: 781-792.

40. Mogaddasi F, Momen Heravi M, Bozorgmehr MR, Ardalant P, Ardalant T
(2010) Kinetic and thermodynamic study on the removal of Methyl orange from Aqueous solution by Adsorption onto camel thorn plant Asian journal of chemistry 22: 5093-5100.

41. Bouchamel N, Merzougui Z, Addoun F (2011) Adsorption en milieux aqueux de deux colorants sur charbons actifs a base de noyaux de datte. J Soc Alger Chim 21: 1-14.

42. Cotoruelo LM, Marqués MD, Francisco JD, José Rodríguez-Mirasol, Juan JR, et al. (2010) Equilibrium and Kinetic Study of Congo Red Adsorption onto Lignin-Based Activated Carbons Transp Porous Med 83: 573-590.

43. Hameed BH, Daud FBM (2008) Adsorption studies of basic dye basic blue 3 (BB3) on activated carbon derived from agricultural waste: Hevea Brasiliensis Seed coat. Chem Eng J 139: 48-55. 